\title{
O JUS POSTULANDI FRENTE AOS DESAFIOS DA INFORMATIZAÇÃO NA JUSTIÇA DO TRABALHO
}

\author{
Autores ${ }^{1}$ \\ Fernanda de Freitas Borges da Silva ${ }^{2}$ \\ Igor Barreto da Costa ${ }^{3}$ \\ Rabech Reis Fernandes ${ }^{4}$ \\ Tatiane Emanuela Vasconcelos Aragão ${ }^{5}$ \\ Virgínia de Brito Almeida da Silva ${ }^{6}$
}

\section{RESUIMO}

Em um Estado Democrático de Direito o acesso à justiça de forma igualitária por todas as classes sociais é algo fundamental, assim, visando alcançar tal pretensão foi criado o instituto do Jus Postulandi, porém, a eficácia deste instituto só foi alcançada no contexto histórico e jurídico da sua criação. Assim, este artigo tem como objetivo apresentar a finalidade do Jus Postulandi e a sua incompatibilidade com o atual cenário da Justiça do Trabalho. Para tanto, utilizou-se como metodologia a pesquisa explicativa, baseada na análise histórica do Jus Postulandi, abordando sua relação com os princípios do Acesso á Justiça, da Simplicidade e da Informalidade; bem como na análise de dispositivos legais e de posicionamentos doutrinários acerca do tema. Ademais, discorre-se sobre o ingresso da parte desacompanhada de advogado à justiça do trabalho e a aplicação desta faculdade na atual dinâmica da Justiça do Trabalho diante da adoção do Processo Judicial Eletrônico (PJe-JT), sendo notado que a complexidade processual trabalhista inviabiliza o amplo acesso à justiça.

PALAVRAS-CHAVES: Jus Postulandi; Processo do Trabalho; PJE; Informatização; Princípios;

\section{RESUMMÉN}

En un Estado Democratico del Derecho, el acceso a la justicia en igualdad de condiciones para todas las clases sociales es fundamental, por lo tanto, con el objetivo de lograr este reclamo, se creó el Instituto Jus Postulandi, sin embargo, la efectividad de este Instituto solo se logró en el contexto histórico y jurídico de su creación. Por lo tanto, este artículo tiene como objetivo presentar el propósito de Jus Postulandi y su incompatibilidad con el escenario actual de Justicia Laboral. Para este propósito, la metodología utilizada fue la investigación explicativa, basada en el análisis histórico de Jus Postulandi, abordando su relación con los principios de Acceso a la Justicia, Simplicidad e Informalidad; así como en el análisis de disposiciones legales y posiciones doctrinales sobre el tema. Además, analiza la entrada de la parte no acompañada de un abogado a la justicia laboral y la aplicación de esta facultad \footnotetext{
Araújo Avelino (E-mail: dravelino@hotmail.com).

${ }^{2}$ Fernanda de Freitas Borges da Silva - E-mail: fernandafreitas77@outlook.com

${ }^{3}$ Igor Barreto da Costa - E-mail: barretocostaigor@gmail.com

${ }^{4}$ Rabech Reis Fernandes - E-mail: rabech9@gmail.com

5 Tatiane Emanuela Vasconcelos Aragão - E-mail: tatimatosbvt@gmail.com

${ }^{6}$ Virgínia de Brito Almeida da Silva - E-mail: vibrito.as@outlook.com
}

1 Trabalho realizado pelos discentes do Curso Bacharelado em Direito na Universidade do Estado da Bahia - UNEB - Campus XIII, vinculado ao componente curricular Direito Processual do Trabalho, sob a regência e orientação do professor Dr. José 
en la dinámica actual de la Justicia Laboral en vista de la adopción del Proceso Judicial Electrónico (PJeJT), y señala que la complejidad del procedimiento laboral hace inviable amplio acceso a la justicia.

PALABRAS CLAVE: Jus Postulandi; Proceso de Trabajo; PJE; Informatización; Principios;

\section{INTRODUÇÃO}

O Jus Postulandi é um instituto processual que permite que a parte provoque o Poder Judiciário sem a necessidade de estar sendo representado por um advogado. Ao longo dos anos foi introduzido na Justiça do Trabalho e atingiu seu auge na Consolidação das Leis Trabalhistas, artigo 791, em 1943. Neste período, o perfil informal, oral e simples dos processos era compatível com esse instituto. Assim, desde o início da sua criação, há uma relação direta entre o Jus Postulandi e os princípios da Simplicidade e Informalidade.

Outrossim, este princípio também tende à privilegiar a ampla defesa e o contraditório, com o objetivo de dar a parte a oportunidade de se defender.

Sendo assim, normativamente, o Jus Postulandi facilita interposição do trabalhador ao judiciário, até porque no sistema jurídico não basta que as decisões sejam socialmente justas, é preciso que ele seja "[...] igualmente acessível à todos [...]" (CAPPELLETTI; GARTH, p.8, 1988).

Esta possibilidade de um trabalhador hipossuficiente pleitear a sua demanda sem advogado facilita o acesso à justiça e promove maior garantia de direitos. Ocorre que, as sucessivas modificações da Justiça do Trabalho, que incluem a complexidade dos tramites processuais, o tecnicismo da linguagem jurídica, a implantação de sistemas eletrônicos (PJE) e a falta de conhecimento dos direitos trabalhistas por parte do trabalhador, transtorna o caráter benéfico do Jus Postulandi ao permitir inferioridade processual daquele que o utiliza. Sendo assim, questiona-se: o Jus Postulandi tem de fato cumprido com a finalidade para a qual foi criado? Este trabalho buscará responder tal pergunta utilizando-se de pesquisas jurisprudenciais, textos de leis e posicionamentos doutrinários, que evidenciaram uma latente desigualdade processual na hodierna aplicação deste princípio.

\section{CONTEXTO HISTÓRICO E CONCEITO DO JUS POSTULANDI}

Os primeiros traços, ainda que superficiais, do Jus Postulandi surgiram no contexto da revolução industrial, com a indústria crescendo a todo vapor produzir mais tornou-se essencial, assim, mais mão de obra era necessária, fazendo com que o número de trabalhadores crescesse significativamente e juntamente com eles os conflitos trabalhistas entre empregado e empregador, visto que as condições de trabalho eram precárias e o empregador ocupava um lugar de opressor nessa relação, explorando até a exaustão os trabalhadores.

Ressalta-se que o Estado pouco intervinha nas relações trabalhistas o que fazia com que os trabalhadores não tivessem qualquer proteção. 
Com o crescente embate entre empregador e empregado, formas de solução de conflitos foram criadas, principalmente na seara administrativa, o que fazia com que os advogados da época não se interessassem pelas causas. Além disso, acontecimentos históricos como a $1^{\text {a }}$ Guerra Mundial impulsionaram a criação de leis trabalhistas, já que o envio de milhões de trabalhadores para as trincheiras ao lado de soldados de outras classes sociais demonstraram a igualdade entre as partes componentes da sociedade. Isto é, para lutar e morrer, os homens eram todos iguais, portanto, deveriam ser iguais para o direito de viver (MARTINEZ, p.84, 2016).

Contudo, foi na Era Vargas, que as relações de trabalho sofreram significativas alterações e passaram a ser regulamentadas por normas estabelecidas pelo Estado, como uma forma de controle dos movimentos operários. Com o decreto n. 1939, Getúlio Vargas promulgou inúmeras leis trabalhistas, onde tais demandas encontraram solução no âmbito do judiciário, surgindo os primeiros fortes indícios do seria o Jus Postulandi. Para Luciano Martinez esta manobra estatal representou um engenho jurídico que legitimava a atuação dos setores opressores da sociedade.

Ademais, administrativamente, foram criadas formas de autocomposição como os Conselhos Permanentes de Conciliação e Arbitragem e Comissões Mistas de Conciliação e Juntas de Conciliação e Julgamento, os quais já traziam em sua formatação o instituto do Jus Postulandi como uma forma de facilitar o acesso do trabalhador na busca pelos seus direitos. "As Comissões Mistas de Conciliação julgava os dissídios coletivos, entretanto, as Juntas de Conciliação e Julgamento julgava os dissídios individuais os quais integravam como partes, os empregados e os empregadores" (MEDICO, 2019).

Outrossim, o Jus Postulandi também foi mencionado expressamente no art. 42 do Decreto Lei $n^{\circ} 1.237$ em 1939, o qual Organizava a Justiça do Trabalho

"Art. 42- O reclamante e o reclamado deverão comparecer pessoalmente á audiência, sem prejuízo do patrocínio de sindicato ou de advogado, provisianado, ou solicitador inscritos na Ordem dos Advogados (BRASIL, 1939)"'.

E em seguida no Decreto $n^{\circ} 6.596$, de 12 de dezembro de 1940, in verbis:
"Art. 90- Os empregados e empregadores poderão reclamar pessoalmente perante a Justiça do Trabalho e acompanhar as suas reclamações até o final.
$\S 1^{\circ}$ - Nos dissídios individuais os empregados e empregadores poderão fazer-se representar por intermédio de sindicato, advogado, solicitador, ou provisionado, inscrito na Ordem dos Advogados do Brasil.
$\S 2^{\circ}$ - Nos dissídios coletivos é facultada aos interessados a assistência por advogado (BRASIL, 1940)"'.

Segundo Bonfim (p. 105, 2008, apud ALVES, p. 1, 2018), no período de 1946, o instituto do Jus Postulandi era compatível com o perfil célere, oral, concentrado, informal, simples e gratuito do processo trabalhista, sendo as demandas casos do cotidiano como: comentário na carteira de trabalho, ressarcimento por despedida injusta, horas extra, férias, dentre outras situações triviais.

Destarte, a figura do Jus Postulandi já se fazia presente antes da criação da Consolidação das Leis Trabalhistas. Contudo, é com a promulgação da CLT, através do Decreto Lei n. 5.452/43, que esse princípio foi consolidado no ordenamento, prometendo celeridade, informalidade, gratuidade e simplicidade para as demandas da época. Assim, a referida legislação trabalhista estabeleceu o instituto no art. 791: "Os empregados e os empregadores poderão reclamar pessoalmente perante a Justiça do Trabalho e acompanhar as suas reclamações até o final", estando em vigor até os dias atuais. 
Hodiernamente, o Jus Postulandi significa o direito de estar em juízo praticando todos os atos necessários ao desenvolvimento do processo. Tal princípio está intimamente ligado ao acesso à justiça, pois permite que a parte sem o auxílio de um advogado atue na sua demanda, principalmente, para aqueles que não possuem condições financeiras para ter tal assessoria jurídica.

\section{O JUS POSTULANDI E OS DEMAIS PRINCÍPIOS DA JUSTIÇA DO TRABALHO}

\subsection{O Jus Postulandi e o Acesso à Justiça}

O acesso à justiça é e deve ser um direito de todos os brasileiros. Entretanto, a justiça nem sempre é algo tão simples e tão barato, assim, a fim de possibilitar o exercício desse direito foi criada a figura do Jus Postulandi.

Como já abordado, o Jus Postulandi é o princípio do direito processual do trabalho que surgiu em 1943 com a Consolidação das Leis do Trabalho, versando sobre a capacidade postulatória em matéria trabalhista. É de senso comum que a capacidade postulatória em nosso cenário nacional se restringe aos advogados devidamente registrados na Ordem dos Advogados do Brasil, entretanto o conceito de Jus Postulandi surgiu justamente para atender aqueles que não tinham como contratar advogados, ou que tivesse outros problemas em matéria postulatória. Destarte, o Jus Postulandi nasceu do princípio do acesso livre à justiça, estando positivado no artigo 791 da CLT.

Após a análise desse instituto que, em síntese, representa a igualdade de postular e o justo processo entre as partes, cabe o seguinte questionamento: 0 Jus Postulandi de fato permite essa igualdade? Muitas são as correntes e opiniões sobre tal fato entre os doutrinadores do direito do trabalho, mas uma chega ao quase consenso entre os estudiosos, que é: a diferença postulatória entre as partes.

É admirável a ideia de uma justiça livre, uma justiça que não se calca em advogados caros e de extrema complexidade em seu processo, é por isso que surgiu o princípio do Jus Postulandi, entretanto, essa visão ainda é utópica, pois não oferece de fato uma chance real à parte hipossuficiente nos processos, basta analisarmos a seguinte cena: de um lado um empregado, que foi demitido após testemunhar em um processo contra a empresa que trabalhava e não teve seus direitos devidamente respeitados e cumpridos pelo empregador, entra com o processo contra este, calcado no princípio do Jus Postulandi, sem um advogado, e assim move o processo até onde consegue sozinho; do outro lado esse mesmo empregador contrata o melhor escritório da cidade, que estuda todo o processo e têm amplo conhecimento na área do direito, buscando todas as saídas possíveis, esgotando o contraditório, diferentemente da parte hipossuficiente. Teria chance o empregado? O princípio do Jus Postulandi e do acesso livre a justiça realmente traz benefícios e democratiza de fato o acesso à justiça?

É claro que em um caso como o exposto anteriormente fica claro que só o instituto do Jus Postulandi não garante a equidade processual entre as partes, o fator econômico por si só não é anulado totalmente pelo instituto, e a parte hipossuficiente ainda sofre as desigualdades processuais.

\subsection{O Jus Postulandi e o Princípio da Simplicidade}

O direito do trabalho e seu processo versam sobre causas de natureza, na maioria das vezes, de caráter emergencial por se tratar de verbas trabalhistas, incluindo salários, que têm o caráter de subsistência pessoal e familiar. É desse ponto de partida que surge o princípio da simplicidade, visto que versa 
sobre pautas tão importantes para a parte mais hipossuficiente da ação. O direito do trabalho e processual do trabalho tem por princípio a simplicidade, o qual tem o objetivo de tornar o processo trabalhista simples, acessível e rápido para que essas problemáticas sejam de pronto resolvidas, seria injusto, por exemplo, que o processo trabalhista fosse tão demorado e complexo quanto os das demais áreas do direito, como a cível, por exemplo.

\subsection{O Jus Postulandi e o Princípio da Informalidade}

Nesta mesma perspectiva de celeridade processual, o princípio da informalidade diz respeito à técnica nos processos trabalhistas e suas formas. Segundo esse princípio a técnica e a forma aplicadas nos processos trabalhistas devem ser sempre que possível as mais simples e céleres, em detrimentos de formas mais complexas e solenes que em muito podem atrasar e dificultar a resolução dos processos, tudo regido pela lei e pelo devido processo legal, devendo o princípio da informalidade ser aplicado sempre que possível.

Assim, os princípios da simplicidade e informalidade são princípios norteadores do direito processual trabalhista direcionados a favorecer a parte mais vulnerável do processo trabalhista, de modo que esses princípios estão intimamente relacionados ao Jus Postulandi, uma vez que garanti que atos processuais trabalhistas sejam feitos pela própria parte desacompanhada de advogado.

Portanto, esses princípios fazem do direito processual do trabalho, pelo menos em parte, mais democrático, fazendo com que a balança da justiça do trabalho diminua a desigualdade existente nos processos judiciais brasileiros.

\section{O INGRESSO DA PARTE DESACOIMPANHADA DE ADVOGADO À JUSTIÇA DO TRABALHO}

O legislador, ao criar o instituto do Jus Postulandi, buscou efetivar o direito social fundamental ao acesso á justiça ao permitir que aqueles que não possuem condições de arcar com honorários advocatícios possam pleitear suas demandas sem um advogado. A Constituição Federal dispõe sobre este direito no art. $5^{\circ}$, XXXV: "A lei não retirará da apreciação do Judiciário lesão ou ameaça a direito".

Ademais, sobre o Jus Postulandi conceitua Sérgio Pinto Martins (p. 196, 2004 apud SOUSA, 2016):

"Uma locução latina que indica o direito de falar, em nome das partes, no processo, que diz respeito a advogado. No processo do trabalho, jus postulandi é o direito que a pessoa tem de estar em juízo, praticando pessoalmente todos os atos autorizados para o exercício do direito de ação, independentemente do patrocínio de advogado".

Esta possibilidade, todavia, está limitada pela Súmula 425 do TST, a qual veda que a parte esteja desacompanhada por um advogado em ação rescisória, ação cautelar, mandado de segurança e recursos de competência do Tribunal Superior do Trabalho. Vejamos:

"JUS POSTULANDI NA JUSTIÇA DO TRABALHO. ALCANCE. Res. 165/2010, DEJT divulgado em 30.04 .2010 e 03 e 4/5/2010 - O jus postulandi das partes, estabelecido no art. 791 da CLT, limita-se às Varas do Trabalho e aos Tribunais Regionais do Trabalho, não alcançando a ação rescisória, a ação cautelar, o 
mandado de segurança e os recursos de competência do Tribunal Superior do Trabalho".

Os legisladores restringiram a figura do Jus Postulandi às Varas do Trabalho e aos Tribunais Regionais do Trabalho com a justificativa da complexidade. Segundo eles, as ações e recursos citados pela súmula 425 requerem processos com rito tradicional e advogados devidamente registrados.

Ressalte-se que o Jus Postulandi, embora frequentemente vinculado ao empregado, também abarca o empregador, conforme estabelece a alínea A do art. 839 da CLT, in verbis: "A reclamação poderá ser apresentada: a) pelos empregados e empregadores, pessoalmente, ou por seus representantes, e pelos sindicatos de classe". Esta capacidade de reclamar não permite a equiparação entre Jus Postulandi e capacidade Postulatória, pois como bem esclarece Sérgio Pinto Martins esta "refere-se ao sujeito e aquele ao exercício do direito pela capacidade de estar em juízo".

Cumpre-se frisar que há questionamentos acerca da recepção do Jus Postulandi no art. 133 da CF e no art. $1^{\circ}$ da lei 8.906/94, que estabeleceu o Estatuto da OAB, já que, em ambas as leis, ressalta-se a necessidade do advogado. $O$ art. 133 da Carta Magna estabelece: "O advogado é indispensável à administração da justiça, sendo inviolável por seus atos e manifestações no exercício da profissão, nos limites da lei".

Todavia o STF, no HC 67.390-2, considerou que a Constituição Federal não invalidou o Jus Postulandi como uma forma de facilitar a defesa e direitos da relação de trabalho. Ademais, no que se refere ao empasse com a legislação da OAB, o julgamento da Ação Direta de Inconstitucionalidade $n^{\circ}$ 1.127 ratificou a indispensabilidade do advogado à administração da Justiça, porém, afirmou que em alguns atos jurisdicionais a sua presença poderia ser dispensada.

Assim, embora haja posicionamentos que considerem o Jus Postulandi como uma violação a norma constitucional, o STF já estabeleceu o seu posicionamento a favor desse instituto.

Desta forma, compreende-se que o princípio do Jus Postulandi foi criado com o objetivo maior de atender a parte hipossuficiente, qual seja o empregado, entretanto pode-se questionar se o empregado consegue compreender a linguagem jurídica, haja vista que a aplicação do direito requer um tecnicismo cada vez mais refinado e uma pequena minoria detém este conhecimento, quais sejam: juristas e operadores do direito.

Além disso, diante da dinâmica deste instituto, surgem outras dúvidas: as partes sairiam de juízo necessariamente com direitos iguais? Caso algo postulado seja indeferido, como uma pessoa que não tem conhecimento técnico poderá perceber falhas ou vícios na sentença, a fim de poder recorrer em juízo? Infelizmente, as repostas revelam uma inferioridade processual assombrosa, como bem afirma o professor Mozart Victor Russomano:

"O resultado disso tudo é que a parte que comparece sem procurador, nos feitos trabalhistas, recai de uma inferioridade processual assombrosa. Muitas vezes o juiz sente que a parte está com o direito a seu favor. A própria alegação do interessado, entretanto, põe por terra sua pretensão, porque mal fundada, mal articulada, mal explicada e, sobretudo, mal defendida. Na condução da prova, o problema se acentua e agrava. $E$ todos sabemos que a decisão depende do que os autos revelarem o que está provado" (Curso de Direito do Trabalho, 9a edição, Curitiba: Editora Juruá, p. 207, 2003). 
Portanto, a realidade demonstra que o Jus Postulandi legitima uma desigualdade processual, pois de um lado está o empregador acompanhado por competentes advogados e do outro o trabalhador sem conhecimento técnico jurídico suficiente para pleitear e acompanhar o processo. $O$ resultado deste desequilíbrio são, muitas vezes, acordos prejudiciais, nos quais o trabalhador, acuado diante de sua desinformação, aceita propostas desfavoráveis. Por isso, presume-se que somente profissionais habilitados poderão acompanhar de forma eficaz todo o andamento processual e ter o conhecimento necessário para se manifestar nos autos, acompanhar prazos e garantir segurança jurídica ao trabalhador.

O Jus Postulandi, conforme os fatos históricos, foi criado em um período em que as demandas eram mais simples. Assim, a atual complexidade do âmbito trabalhista incompatibiliza o acesso da parte desacompanhada à Justiça do Trabalho. Isto é, como bem afirma Dayse Coelho de Almeida "[...] se do lado normativo o trabalhador encontra-se de todas as formas possíveis e imagináveis protegido, do lado processual foi abatido pelas pernas, impossibilitado de caminhar [...] se combate tudo neste país, menos a desinformação em relação aos direitos trabalhistas" (Boletim Jurídico, a. 1, n 100, 2004).

\section{A IMPLANTAÇÃO DO PJE (PROCESSO JUDICIAL ELETRÔNICO) NA JUSTIÇA DO TRABALHO COMO OBSTÁCULO AO JUS POSTULANDI}

É certo que com a globalização, a tecnologia ampliou seus horizontes estando cada vez mais presente em todos os âmbitos da sociedade, modernizando e facilitando a realização de atividades. Desta forma, o judiciário foi um dos ambientes no qual a implantação da tecnologia trouxe modernização, atribuindo mais celeridade, praticidade e eficiência a prestação jurisdicional.

Tal informatização foi possível com a Lei n. 11.419 de 2006, chamada de Lei do Processo Eletrônico, a qual inseriu no sistema judiciário os meios eletrônicos com o objetivo de maior celeridade na pacificação dos conflitos. A partir da promulgação dessa lei, novas resoluções foram aprovadas a fim de planejar, estruturar e organizar a informatização do Poder Judiciário.

A justiça do trabalho foi uma das pioneiras no processo de modernização, de modo que em 2012, o Conselho Superior da Justiça do Trabalho editou a Resolução n. 94 instituindo o Processo Eletrônico Judicial da Justiça do Trabalho (PJe-JT), por meio do qual todos os atos processuais seriam realizados.

Nesse contexto, a criação dos sistemas eletrônicos no judiciário, a exemplo do PJe, permitiu que os processos fossem analisados e julgados mais rapidamente, facilitando o acesso e o acompanhamento dos atos processuais, promovendo segurança e economia de custos operacionais, orçamentarias e ambientais, fazendo com que o propósito dos princípios da simplicidade, informalidade, economia processual e da celeridade fossem melhor aplicados. Segundo, o renomado autor Leone Pereira, " [...] sempre que possível, os excessos do formalismo e da burocracia devem ser eliminados, na medida em que a busca da efetiva prestação jurisdicional e do acesso à ordem jurídica justa devem ser uma constante" (p. 84, 2016).

No mais, no que se refere ao âmbito da Justiça do Trabalho, os benefícios trazidos pela modernização e informatização não são diferentes dos já citados, porém, quando se busca a aplicação e efetividade do Jus Postulandi, a implantação do PJ-e revela-se como um obstáculo ao acesso à justiça, pois, ao passo que permite mais celeridade ao processo ele também afasta as pessoas que vão à Justiça do Trabalho sem a representação de um advogado, visto que o acesso e uso do PJ-e requer de quem o usa um 
conhecimento técnico, o que muitas vezes essas pessoas não possuem, visto que, não raras vezes, são pessoas simples e hipossuficientes, com baixa escolaridade, ou seja, acaba afastando da tutela do Estado aqueles os quais se busca proteger.

Entre os obstáculos criados pela implantação do PJ-e está a exigência de certificado digital para que a parte possa protocolar qualquer petição; a obrigatoriedade de utilização de assinatura digital para ter acesso ao sistema, ou, no caso do Jus Postulandi, a necessidade de ser feita por intermédio de um servidor (art. 791, CLT), podendo apresentar as peças processuais e documentos em papel nos locais competentes para recebimento, que serão digitalizadas e juntadas aos autos eletrônicos, entre ouros.

Assim, percebe-se que o acesso ao PJ-e ainda é muito restrito, uma vez que as exigências feitas para ter acesso ao sistema distancia a parte que faz uso do Jus Postulandi da justiça. Ademais, quanto aos servidores protocolarem as peças e documentos das partes que não tem acesso ao PJ-e é evidente a mitigação desse princípio, haja vista que a finalidade do Jus Postulandi é dar autonomia as partes, e nesse caso, acontece exatamente o oposto, visto que a parte depende da disponibilidade, e muitas vezes da boa vontade do servidor. Outro fator que impede a eficácia do Jus Postulandi é o acesso à internet, uma vez que, apesar de hoje grande parte da população ter acesso à internet, isso ainda não é uma realidade de todas as classes sociais.

Portanto, percebe-se que há uma mitigação do Jus Postulandi promovida pelo próprio PJ-e, prejudicando apenas aqueles que não são assistidos por advogado, de modo que é necessária a reformulação do sistema eletrônico, adaptando-o para que as pessoas que optarem por não ser representadas tenham acesso e saibam manusear o sistema.

\section{CONSIDERAÇÕES FINAIS}

O Jus Postulandi surgiu como uma forma de garantir que a parte hipossuficiente de uma relação trabalhista possa pleitear a tutela jurisdicional dos seus direitos sem a necessidade de ser representada por um advogado, lhe permitindo adentrar no universo jurídico e ter o seu direito analisado, sem prejuízo da eficácia, legalidade e justiça através de uma justiça mais simples e informal. Ademais por se tratar de relações de trabalho, as quais são a principal forma de subsistência do ser humano, esses princípios norteadores são de fato louváveis, porém, o Jus Postulandi enfrenta inúmeros problemas para cumprir com a finalidade para qual foi criado.

Tais problemas são perceptíveis desde o contexto histórico da sua criação, no qual os conflitos trabalhistas eram de menor complexidade, ou seja, eram demandas mais simples que não exigiam do trabalhador extenso conhecimento técnico e jurídico para pleitear seus interesses, além disso, as demandas trabalhistas naquela época não tinha uma maior participação dos advogados, visto que eram demandas debatidas, em grande parte, na seara administrativa, sendo poucos os empregadores representados por advogados, o que equilibrava a situação.

Contudo, atualmente, as demandas trabalhistas possuem um nível de complexidade muito maior e a participação dos advogados nas causas trabalhistas é muito mais expressiva da que era inicialmente, de modo que o trabalhador fica desprotegido, pois necessita de um conhecimento jurídico que não possui e de uma representação pela qual optou não ter, enquanto o empregador, o qual já possui uma posição privilegiada em relação ao trabalhador está sendo representado por advogado. Dessa forma, o Jus Postulandi acaba promovendo uma desigualdade entre as partes na relação trabalhista. 
Uma afirmação que pode surgir ao debater o princípio do Jus Postulandi e a possível desigualdade entre as partes, é a posição do juiz nessa relação, o qual tem a obrigação de saber o direito e conduzir todo o andamento dos atos processuais, de modo que o empregado não estaria em desvantagem ao optar por não ser representado por advogado, porém o juiz deve se manter imparcial, de modo que ele não poderia intervir no processo protegendo o interesse da parte como o advogado faria, desse modo o trabalhador estaria em uma posição desfavorável em relação ao empregador.

Ademais, vale destacar que o próprio TST ao editar a súmula 425 criando as limitações ao Jus Postulandi só reforça a ideia de que a parte que escolhe fazer uso desse princípio não possui conhecimento técnico e jurídico suficiente para exercer todos os atos processuais, visto que não poderá interpor recursos nem propor ação rescisória ou cautelar, bem como não poderá impetrar mandado de segurança. Destarte, observa-se que essa súmula vai contra a finalidade desse princípio, já que, levando em consideração a complexidade que as demandas trabalhistas foram adquirindo ao longo do tempo, se a parte tem conhecimento jurídico suficiente para postular nas instanciais iniciais, também terá para praticar todos os atos processuais, inclusive em sede recursal, até o trânsito em julgado da demanda.

Assim, essas limitações vão contra a finalidade para a qual o Jus Postulandi foi criado, qual seja permitir o acesso à justiça pela parte hipossuficiente, de modo que a parte não poderá exercer alguns atos processuais por estar desacompanhada de advogado, obrigando o empregado a contratar os serviços de um operador do direito ou ficar sem exercer os atos necessários ao andamento da ação, restando prejudicada a ampla defesa, tendo em vista que o trabalhador não poderá esgotar todos os meios ou argumentos oferecidos pelo Direito para defender seus interesses.

Outrossim, como explicitado ao longo deste artigo, outro problema para a efetiva aplicação do Jus Postulandi está na informatização do Poder Judiciário com a implementação do PJ-e JT, uma vez que o objetivo do Jus Postulandi é proporcionar as pessoas que não possuem condições de arcar com a contratação de um advogado a possibilidade de acionar o judiciário, porém, o público do Jus Postulandi trata-se de pessoas hipossuficientes que não possuem conhecimento técnico ou muitas vezes meios para acessar o PJ-e, visto que existem inúmeros requisitos para que a parte se cadastre e protocole as petições (certificado digital, assinatura eletrônica), e nem conhecimento jurídico para postular sem o auxílio de um advogado.

É notório que o princípio do Jus Postulandi não cumpre totalmente com a finalidade para a qual foi criada, devendo se adequar à realidade da justiça do trabalho, uma vez que o processo trabalhista está cada vez mais técnico e complexo, caso contrário esse instituto pode acabar em desuso. Destarte, podese dizer que o Jus Postulandi tem sido um falso acesso à justiça, de modo que, apesar de permitir que a parte possa ingressar na justiça para demandar por seus interesses sem a representação de um advogado, não proporciona meios para que ela tenha o devido êxito na prática dos atos processuais, visto que o empregado não possui o conhecimento técnico e jurídico necessário para agir na defesa dos seus direitos.

Portanto, o Jus Postulandi pode ter sido uma solução para o período histórico no qual foi criado, mas com a complexidade das relações trabalhistas, alterações legislativas, informatização do judiciário e a falta de adaptação do instituto a essas mudanças, bem como a falta de qualquer aparato que proporcione aos seus usuários a capacitação necessária (cursos) para a prática de tais atos e o pleno acesso ao PJ-e, fez com o Jus Postulandi perdesse aos poucos sua eficácia, de modo que hoje esse instituto não tem demonstrado ser essencial ao acesso à justiça. 


\section{REFERÊNCIAS BIBLIOGRÁFICAS}

ALMEIDA, Dayse Coelho de. A quem interessa a continuidade do Jus Postulandi na Justiça do Trabalho?. Boletim Jurídico, Uberaba/MG, a. 3, no 100 . Disponível em: $<$ https://www.boletimjuridico.com.br/ doutrina/artigo/397/a-quem-interessa-continuidade-juspostulandi-justica-trabalho> Acesso em: 18 fev. 2020.

ALVES, Kétina Acelino. Jus postulandi na Justiça do Trabalho e o efetivo acesso à justiça: uma análise da sua (in) eficácia. Jus, 2018. Disponível em: <https://jus.com.br/artigos/70840/jus-postulandi-na-justicado-trabalho-e-o-efetivo-acesso-a-justica-uma-analise-da-sua-in-eficacia/l>. Acesso em: 10 de fevereiro de 2020.

BRASIL. Constituição da República Federativa do Brasil de 1988. Planalto. Disponível em: $<$ http://www.planalto.gov.br/ccivil_03/constituicao/constituicao.htm>. Acesso em 14 de fevereiro de 2020.

Decreto-lei no 1.237, de 2 de maio de 1939 - Publicação Original. Câmara dos deputados. Disponível em : <https://www2.camara.leg.br/legin/fed/declei/1930-1939/decreto-lei-1237-2-maio1939-349344-publicacaooriginal-1-pe.html>. Acesso em: 10 de fevereiro de 2020.

Decreto $\mathrm{n}^{\circ}$ 6.596, de 12 de dezembro de 1940. Câmara dos deputados. Disponível em: <https://www2.camara.leg.br/legin/fed/decret/1940-1949/decreto-6596-12-dezembro-1940-330725norma-pe.html>. Acesso em: 11/02/2020.

Consolidação das Leis Trabalhistas. Decreto-lei $n^{\circ} 5.452$, de $1^{\circ}$ de maio de 1943. Planalto. Disponível em: <http://www.planalto.gov.br/ccivil_03/Decreto-Lei/Del5452.htm>. Acesso em: $11 / 02 / 2020$

. Estatuto da Advocacia e a Ordem dos Advogados do Brasil (OAB). LEI N ${ }^{\circ}$ 8.906, DE 4 DE JULHO DE 1994. Disponível em: <http://www.planalto.gov.br/ccivil_03/leis/18906.htm>. Acesso em: $18 \mathrm{de}$ fevereiro de 2020.

Supremo Tribunal Federal. Ação Direta de Inconstitucionalidade ${ }^{\circ}$ 1127. Disponível em: $<$ http://portal.stf.jus.br/processos/detalhe.asp?incidente=1597992 $>$. Acesso em: 14 de fevereiro de 2020.

. Tribunal Superior do Trabalho. Súmula ${ }^{\circ} 425$ - Jus Postulandi na justiça do trabalho. Alcance. Disponível em: <http://www.tst.jus.br/noticias/-/asset_publisher/89Dk/content/tst-aprova-redacaoda-sumula-425-sobre-o-jus-postulandi>. Acesso em 15 de fevereiro de 2020.

CAMARGOS, Maria Eduarda. Princípios do Direito Processual do Trabalho. Jusbrasil. 2017. Disponível em: <https://dudacamargos.jusbrasil.com.br/artigos/462947801/principios-do-direito-processual-dotrabalho>. Acesso em : 14 de fevereiro de 2020.

CAPPELLETTI, M; GARTH, B. Acesso à Justiça. Tradução de Ellen Gracie Northfleet. Porto Alegre, Fabris, 1988.

CARDEL, Renato de Souza. O Processo Judicial eletrônico e o jus postulandi na Justiça do Trabalho. Juslaboris, 2017. 
$<$ https://juslaboris.tst.jus.br/bitstream/handle/20.500.12178/144333/2017_cardel_renato_processo_ju dicial.pdf?sequence=1\&isAllowed=y>. Acesso em :11 de fevereiro de 2020.

FALCÃO, Ismael Marinho. O jus postulandi frente ao novo ordenamento constitucional. Jus. 1999. Disponível em: <https://jus.com.br/artigos/1250/o-jus-postulandi-frente-ao-novo-ordenamentoconstitucional $>$. Acesso em: 19 de fevereiro de 2020.

FREITAS, Danielli Xavier. O Ius Postulandi na Justiça do Trabalho e o PJE: a problemática do acesso à justiça.

Jusbrasil, 2014.

Disponível em: $<$ https://daniellixavierfreitas.jusbrasil.com.br/artigos/145366043/o-ius-postulandi-na-justica-dotrabalho-e-o-pje-a-problematica-do-acesso-a-justica>. Acesso em :14 de fevereiro de 2020.

MARTINEZ, Luciano. Curso de direito do trabalho : relações individuais, sindicais e coletivas do trabalho /Luciano Martinez. - 7. ed. — São Paulo : Saraiva, 2016

MARTINS, A. ; ANDRADE, S. Jus postulandi na Justiça do Trabalho: Possibilidade, benefícios e malefícios. LexMagister. Disponível em: <https://www.lex.com.br/doutrina_27437558_JUS_POSTULANDI_NA_JUSTICA_DO_TRABALHO_POSSI BILIDADE_BENEFICIOS_E_MALEFICIOS.aspx>. Acesso em 14 de fevereiro de 2020.

MEDICO, Patrícia. História e Evolução do Direito do Trabalho no Mundo e no Brasil. Jusbrasil, 2019. Disponível em: <https://patriciamedico.jusbrasil.com.br/artigos/654731375/historia-e-evolucao-dodireito-do-trabalho-no-mundo-e-no-brasil?ref=serp>. Acesso em: 10 de fevereiro de 2020.

NASCIMENTO, Amauri Mascaro. In "Curso de Direito Processual do Trabalho", Ed. Saraiva, São Paulo, $15^{\mathrm{a}}$ ed., 1994, págs. 188/190

PEREIRA, Leone.Manual de processo do trabalho / Leone Pereira. - 5. ed. - São Paulo : Saraiva, 2018, p.77.

RUSSOMANO, Mozart Victor. In "Comentários à Consolidação das Leis do Trabalho", Ed. Forense, Rio de Janeiro, 1983, pág. 853.

SOUSA, Marcos Junior de. O Jus Postulandi e a Justiça do Trabalho. Jusbrasil, 2016. Disponível em: $<$ https://marcosjuniodesousa.jusbrasil.com.br/artigos/403601682/o-jus-postulandi-e-a-justica-dotrabalho>. Acesso em: 10 Fev.2020; 